\title{
Erratum to: Geo-electrical soundings and analysis to investigate groundwater aquifers at Khulna City, coastal area of Bangladesh
}

\author{
Md. Ibrahim Khalil • Golam Rasul • Ratan Kumar Majumder • Mohammad Zafrul Kabir • \\ Farah Deeba • Farhana Islam • Shanjib Karmaker • K. M. Jalal Uddin Rumi • \\ Rahnuma Siddique
}

Published online: 20 December 2014

(C) Saudi Society for Geosciences 2014

\section{Erratum to: Arab J Geosci}

\section{DOI 10.1007/s12517-014-1636-Z}

Regrettably, the online version of this article contained an error.

Several authors were omitted in the original version. The complete list of authors is given and above and their affiliations are listed below as well as Dr. Khalil's updated affiliation.

In addition, a typographical error was found in the Abstract, line 2; "coastal city srea" should read "coastal city area."

Further, Ibrahim Khalil's name should be Md. Ibrahim Khalil. His correct name is reflected on this article.

The online version of the original article can be found at http://dx.doi.org/ 10.1007/s12517-014-1636-Z.

M. I. Khalil $(\bowtie) \cdot$ G. Rasul • R. K. Majumder · M. Z. Kabir •

F. Deeba

Nuclear Minerals Unit, Atomic Energy Research Establishment,

Bangladesh Atomic Energy Commission, Savar, Dhaka 1349,

Bangladesh

e-mail: ibrahim_baec@hotmail.com

G. Rasul

e-mail: grasulgeo@yahoo.com

R. K. Majumder

e-mail: ratankm@yahoo.com

M. Z. Kabir

e-mail: zafkab_geoaec@yahoo.com

F. Deeba

e-mail: fdeeba_geoaec@yahoo.com

F. Islam $\cdot$ S. Karmaker $\cdot$ K. M. J. U. Rumi $\cdot$ R. Siddique

Nuclear Power and Energy Division, Bangladesh Atomic Energy

Commission, Ramna, Dhaka 1000, Bangladesh

F. Islam

e-mail: prakrity98@yahoo.com

S. Karmaker

e-mail: shanjib_baec@yahoo.com

K. M. J. U. Rumi

e-mail: rumi_baecgeo@yahoo.com

R. Siddique

e-mail: rahnuma_070@yahoo.com 